\title{
Assessment of pain-related fear in individuals with chronic painful conditions
}

\section{Manasi M Mittinty' \\ Daniel W McNeil2,3 \\ David S Brennan' \\ Cameron L Randall ${ }^{4}$ \\ Murthy N Mittinty ${ }^{5}$ \\ Lisa Jamieson'}

'Australian Research Centre for Population Oral Health, Adelaide Dental School, The University of Adelaide, Adelaide, SA, Australia; ${ }^{2}$ Department of Dental Practice and Rural Health, School of Dentistry, West Virginia University, Morgantown, WV, USA; ${ }^{3}$ Department of Psychology, Eberly College of Arts and Sciences, West Virginia University, Morgantown, WV, USA; ${ }^{4}$ Department of Oral Health Sciences, University of Washington School of Dentistry, Seattle, WA, USA; ${ }^{5}$ School of Public Health, The University of Adelaide, Adelaide, SA, Australia

Correspondence: Manasi M Mittinty Australian Research Centre for Population Oral Health, Adelaide Dental School, The University of Adelaide, Level 9, 57 North Terrace, AHMS Building, Adelaide 5006, SA, Australia

Email manasi.mittinty@adelaide.edu.au
This article was published in the following Dove Press journal: Journal of Pain Research

\begin{abstract}
Background: Heightened fear and anxiety related to pain may result in emotional and behavioral avoidance responses causing disability, distress, and depression. Fear and anxiety associated with pain can potentially change the course of the pain experience. It is plausible that fear and anxiety related to pain affect the duration and frequency of pain experienced by the patient.
\end{abstract}

Aim: The study aimed to examine the applicability of the Fear of Pain Questionnaire-III (FPQ-III) in identifying who are likely to report longer duration and greater frequency of pain experience. Methods: To test this hypothesis, a cross-sectional study was conducted with 579 individuals from a community-based sample living with chronic pain. The factor structure and validity of FPQ-III in the community-based sample were also tested.

Results: The findings suggest higher fear of severe pain but lower fear of medical pain, associated with longer duration and more frequent pain experience. The analysis also confirmed the three-factor structure of FPQ-III, demonstrating good internal consistency for fear of severe pain (0.71) and fear of medical pain (0.73) and acceptable range for fear of minor pain (0.65). Conclusion: These findings suggest that the FPQ-III can be potentially applied to identify individuals at risk for prolonged continuous pain and as a screening tool to measure fear and anxiety related to pain.

Keywords: fear of pain, fear related to pain, chronic pain, duration of pain, frequency of pain

\section{Introduction}

Chronic pain is a highly prevalent, complex, and comorbid disorder, ${ }^{1}$ which not only affects the individual but also their family, friends, employers, and communities. ${ }^{2}$ It carries significant economic burden associated with the costs related to health care expenses, loss of work productivity, medical leave, and pension. Between $30 \%$ and $50 \%$ of the global population are reported to suffer from moderate-to-severe chronic pain. ${ }^{3}$ Despite increasing research and clinical attention, it remains a major public health issue due to lack of complete understanding of the myriad of factors, including emotions, that affect the experience and expression of pain.

Chronic pain is a physical-emotional experience that impairs physical functioning, ability to perform everyday activities, and engagement in social events, which causes varying degrees of anxiety, fear, worry, and anger. Chronic pain patients are at major risk for depression and suicide. ${ }^{4-6}$ Literature shows that pain can be driven, maintained, and at times augmented by these psychosocial factors (eg, fear, anxiety, stress, and depression) ${ }^{7,8}$ Studies show that the emotional and behavioral responses to pain are strongly guided by two related psychosocial factors, fear and anxiety. ${ }^{9-12}$ Individuals with high 
fear and anxiety are more likely to infer pain as damaging, which instigates escape behaviors like avoidance of movement and activity, ${ }^{13-15}$ catastrophizing, ${ }^{16}$ and hypervigilance. ${ }^{17}$ On the contrary, individuals who have lower fear and anxiety do not interpret pain so negatively, which aids their recovery and healing process. ${ }^{18}$ Fear and anxiety also affect anticipation of future painful experiences, and thereby reduce pain inhibition, magnifying pain sensitivity. Thus, fear and anxiety can alter the course of pain experience. It is therefore necessary to enhance the understanding of these constructs as related to pain to provide optimal care for chronic pain patients.

Multiple scales have been developed to measure concepts of fear and anxiety related to pain in adults. These include the Fear-Avoidance of Pain Scale, ${ }^{19}$ Fear Avoidance Beliefs Questionnaire, ${ }^{18}$ Fear of Pain Questionnaire-III (FPQ-III), ${ }^{20}$ Pain Anxiety Symptoms Scale, ${ }^{21}$ and the Tampa Scale of Kinesphobia. ${ }^{22}$ Although these tools share somewhat overlapping concepts surrounding fear related to pain, rumination, pain-related anxiety, avoidance behavior, and catastrophizing, there is distinct difference in their application. Most of these scales focus on emotions and feelings of an individual with an existing pain condition.

The FPQ-III is unique, however, in that it assesses painrelated fear and anxiety, providing norms for both patient and general population groups. The FPQ-III ${ }^{20}$ measures three domains of fear and anxiety associated with pain: fear of severe pain, fear of minor pain, and fear of medical pain. The validity and reliability of the FPQ-III have been assessed in healthy participants, college students, dental patients, and chronic pain patients with major psychiatric diagnosis..$^{20,23-28}$ However, its applicability in identifying individuals likely to experience longer duration and greater frequency of pain from a community-based sample has not previously been examined. Therefore, this study aimed to examine the association between subscales of the FPQ-III and duration and frequency of pain in individuals from a community-based sample. The factor structure and validity of FPQ-III in the sample were also tested.

\section{Methods}

\section{Study design and participants}

Participants completed an online survey that was developed for a larger cross-sectional study examining relations between fear and anxiety related to pain, coping strategies, patient-anticipated outcomes, and health-related quality of life. The survey was conducted between July and October 2017, using a web-based platform, Survey Monkey, ${ }^{29}$ that is routinely used to conduct health-related surveys. The survey collected information on demographics, pain history, coping strategies, patient-anticipated outcomes, and health-related quality of life, in addition to fear and anxiety related to pain. The detailed protocol for this study was published ${ }^{30}$ prior to conducting the survey. Organizations and patient forums that support the well-being of chronic pain patients were employed to advertise the study. The study has ethics approval from the Human Research Ethics Committee of The University of Adelaide (approval number H-2017-068). All participants provided digital informed consent prior to participating in the study.

\section{Participants}

Participants met the following inclusion criteria to participate in the study: 1) age 18 years and above, 2) experiencing pain for $>6$ months, and 3) proficient in English language. No inducement for participation was offered. Participants were asked to answer each item from their own experience and general knowledge about pain.

\section{Measures}

\section{Sociodemographic information}

Sociodemographic information such as age, sex, marital status, education, and employment status was collected. As these sociodemographic factors (age, ${ }^{31}$ marital status, ${ }^{32}$ and education and employment ${ }^{33-35}$ ) are reported to have significant impact on the experience of chronic pain, they were treated as independent variables in the initial models.

\section{Pain-related factors}

Participants provided information about the duration, severity, and frequency of the pain they had experienced in the 2 weeks prior to participating in the survey. This interval was chosen to minimize recollection bias, based on a prior study. ${ }^{36}$ For duration, participants chose from the following options: 1) 6-12 months, 2) 1-5 years, 3) 6-10 years, and 4) 11 years or more. For severity, participants chose from the following: 1) 1 (no pain), 2) 2 (mild pain), 3 ) 3 (moderate pain), 4) 4 (severe pain), and 5) 5 (worst imaginable pain). For frequency, participants chose from the following: 1) 1 (1-3 days), 2) 2 (4-6 days), 2) 3 (7-9 days), 4) 4 (10-12 days), and 5) 5 (everyday/continuous pain).

\section{FPQ-III}

The FPQ-III consists of 30 items, each describing a painful experience. Each participant rated how fearful they felt or would feel about experiencing pain presented in each item. Every item is scored using a 5-point Likert scale ranging 
from 1 (not afraid at all) to 5 (extremely afraid). The 30 items measure three subscales: fear of severe pain, fear of minor pain, and fear of medical pain. Each subscale is scored by summing item responses. Higher scores indicate greater fear. The FPQ-III has high test-retest reliability $(r=0.92)$ and internal consistency $(\alpha=0.74)$, which has been confirmed by other studies. $^{23-28}$

\section{Statistical analyses}

Association between FPQ-III subscales and longer duration and higher frequency of pain

To examine the applicability of FPQ-III in identifying individuals more likely to experience pain frequently and/ or for longer periods of time, univariate logistic regression was performed. For the analysis, sociodemographic factors and the three subscales of FPQ-III (ie, fear related to severe pain, fear related to minor pain, and fear related to medical pain) were treated as independent variables, and severity, duration, and frequency of pain were treated as the outcomes. All analyses were performed in STATA 14.1. ${ }^{37}$ The number of cases across the specified categories was sparse and at times null, and hence needed to be recoded as binary variables. The categories recoded were as follows: age as "1" for age 18-40 years and "2" for age $41+$ years, marital status as " 1 " if married or single but cohabiting and " 2 " if separated/single/divorced/widowed, education level were indicated as " 1 " for school completed/ bachelor's degree, "2" for postgraduate education, and "3" others (certificate course/self-employed). Similarly, the outcome categories, duration of pain was recoded as " 1 " for 6 months to 5 years and " 2 " for $6+$ years; frequency of pain was recoded as " 1 " for noncontinuous pain and " 2 " for continuous pain.

\section{Factor structure}

A three-factor structure for the FPQ-III has previously been found in healthy participants, ${ }^{20}$ dental pain patients, ${ }^{20}$ and chronic pain patients with major psychiatric diagnosis such as depression and psychoactive substance use. ${ }^{27}$ In this study, confirmatory factor analysis was used to determine the factor structure of pain-related fear and anxiety in individuals living with chronic pain from a community-based sample who self-reported their experience of chronic painful conditions. As opposed to an exploratory factor analysis, which is a theory-generating model, ${ }^{38}$ confirmatory factor analysis is a theory-testing model reflected by the number of factors generated in previous studies. Therefore, in this study, we restricted the factors to the previously identified three fac- tors. ${ }^{20}$ The factor analysis was conducted in STATA ${ }^{37}$ using the factor command and the varimax rotation to keep the components orthogonal/uncorrelated. The fit of the model to the data was evaluated by the chi-square value, the root mean square error of approximation (RMSEA), the coefficient of determination (CD), and the comparative fit index (CFI). A satisfactory fit model should have RMSEA $<0.05$, $\mathrm{CFI}>0.9$, and $\mathrm{CD}>0.9$.

\section{Reliability}

To measure the internal consistency of FPQ-III subscales and to test how closely items in each subscale were related, Cronbach's $\alpha$ was measured as the coefficient of reliability. Commonly, a Cronbach's $\alpha$ value of 0.7 or more is considered an indication of adequate internal consistency. ${ }^{39}$ However, it is necessary to apply this threshold with caution when $\alpha$ is computed from ordinal items. ${ }^{40,41}$ Evidence shows that greater number of items can magnify the value of $\alpha$, while fewer items can lower the value of $\alpha .^{40}$ For a larger sample, $\alpha$ represents lower limit. Furthermore, the appropriate degree of reliability depends on the use of the instrument. For example, an instrument may be less reliable if it is a part of a battery of tests and has fewer items. It is for this reason we set the threshold value of Cronbach $\alpha$ at 0.6 using the formula:

$$
\alpha=\frac{N \cdot \bar{c}}{\bar{v}+(N-1) \cdot \bar{c}}
$$

where, $N=$ number of items, $\bar{c}=$ average interitem covariance among the 30 items, and $\bar{v}=$ the average variance.

\section{Results}

Of the initial 579 respondents, 89 had incomplete information and were excluded from the analyses. The final sample size was 490 , which exceeded the target size of $480,{ }^{30}$ calculated using the simple random sampling approach.

\section{Descriptive statistics}

Table 1 presents descriptive statistics for the sample $(n=490)$, which was $93 \%$ female. The age range of the sample was $18-80$ years. Participation was highest among those aged 31-40 years (ie, 28\%), followed by those aged $41-50$ years (ie, $25 \%$ ). Most participants were from Australia (ie, $60 \%$ ) and were married or cohabiting with a partner (ie, 66\%). The sample was relatively well educated, with $51 \%$ having a Bachelor's degree or postgraduate training and reported earning middle income (ie, 54\%). Most participants reported suffering from pain for 6 or more years (ie, $62 \%$ ). 


\section{Fit indices}

The chi-square value of the final model was 1,197 with $355 \mathrm{df}$ (degrees of freedom) and the significance of the chi-square test $(P<0.001)$. The RMSEA is 0.07 (95\% CI $0.06-0.07$ ) for the model, the CFI is 0.909 , and CD is 0.996 .

Table I Number and percentage for demographic characteristics

\begin{tabular}{|c|c|c|}
\hline Variables & Number (n) & Percentage \\
\hline \multicolumn{3}{|l|}{ Age (years) } \\
\hline $18-30$ & 128 & 23 \\
\hline $31-40$ & 153 & 28 \\
\hline $4 I-50$ & 135 & 25 \\
\hline $51-60$ & 84 & 15 \\
\hline $60+$ & 50 & 9 \\
\hline \multicolumn{3}{|l|}{ Sex } \\
\hline Male & 40 & 7 \\
\hline Female & 510 & 93 \\
\hline \multicolumn{3}{|l|}{ Education level } \\
\hline Schooling completed & 144 & 26 \\
\hline Bachelor's degree & 136 & 25 \\
\hline Postgraduate training & $|5|$ & 28 \\
\hline Others & 119 & 22 \\
\hline \multicolumn{3}{|l|}{ Currently employed } \\
\hline Yes & 304 & 55 \\
\hline No & 246 & 45 \\
\hline \multicolumn{3}{|l|}{ Family income } \\
\hline Low & 202 & 37 \\
\hline Middle & 295 & 54 \\
\hline High & 53 & 10 \\
\hline \multicolumn{3}{|l|}{ Marital status } \\
\hline Married & 270 & 49 \\
\hline Divorced & 32 & 6 \\
\hline Separated & 18 & 3 \\
\hline Widowed & 8 & 1 \\
\hline Single but cohabiting & 92 & 17 \\
\hline Single & 130 & 24 \\
\hline \multicolumn{3}{|l|}{ Length of pain } \\
\hline \multicolumn{3}{|l|}{ condition } \\
\hline 6-12 months & 35 & 6 \\
\hline $2-5$ years & 170 & 31 \\
\hline $6-10$ years & 156 & 28 \\
\hline$>11$ years & 189 & 34 \\
\hline \multicolumn{3}{|l|}{ Severity of pain in last } \\
\hline \multicolumn{3}{|l|}{2 weeks } \\
\hline No pain & 4 & 0.7 \\
\hline Mild pain & 45 & 8 \\
\hline Moderate pain & 260 & 47 \\
\hline Severe pain & 206 & 37 \\
\hline Worst pain & 35 & 6 \\
\hline \multirow{2}{*}{\multicolumn{3}{|c|}{$\begin{array}{l}\text { Frequency of pain in } \\
\text { last } 2 \text { weeks }\end{array}$}} \\
\hline & & \\
\hline I-3 days & 26 & 8 \\
\hline 4-6 days & 59 & 11 \\
\hline 7-9 days & 64 & 12 \\
\hline $10-12$ days & 58 & 11 \\
\hline Everyday & 343 & 62 \\
\hline
\end{tabular}

Although, chi-square indicates that the model is not the best fit, RMSEA and CD show that the model is acceptable fit for the data.

\section{Association between FPQ-III subscales and longer duration and higher frequency of pain}

To test whether there was an association between the FPQIII subscales and duration and frequency of pain, logistic regression models were used. In the preliminary model, all demographic factors (ie, age, marital status, education level, employment status, and income) and the three subscales of the FPQ-III were added as independent variables. Some factors were not found to be statistically significant and were not included in the final regression model. The final model was composed only of statistically significant predictors, which were two demographic factors (ie, age and employment) and the three subscales of FPQ-III.

For duration of pain (Table 2), younger participants were $46 \%$ less likely to report longer duration of pain. Participants who were not employed were also $60 \%$ more likely to report longer duration of pain. In addition, the findings suggest that higher fear of severe pain and lower fear of medical pain are associated with longer duration of pain experience.

For frequency of pain (Table 3), the logistic regression analysis suggests that younger participants were $43 \%$ less likely to report more frequent experience of pain. Participants who were not employed were $80 \%$ more likely to report more frequent experience of pain. In addition, the findings suggest that higher fear of severe pain and lower fear of medical pain are associated with more frequent pain experience. The "acute" nature of medical pain compared with the "chronic nature" of severe pain related to accidents may explain the report of longer duration and more frequent pain experience by individuals with higher fear of severe pain.

Table 2 Results from logistic regression model predicting longer duration of pain

\begin{tabular}{|l|l|l|l|}
\hline Duration of pain & Odds ratio & $P$-value & $\mathbf{9 5 \%} \mathbf{~ C l}$ \\
\hline $\begin{array}{l}\text { Age } \\
\quad \text { I8-40 years }\end{array}$ & 0.54 & 0.01 & $0.37-0.80$ \\
Employment status & & & \\
$\quad$ No & 1.60 & 0.01 & $1.14-2.50$ \\
Fear of pain subscales & & & \\
Severe & 1.40 & 0.01 & $1.12-1.84$ \\
Minor & 0.80 & 0.10 & $0.62-1.04$ \\
Medical & 0.77 & 0.01 & $0.61-0.98$ \\
\hline
\end{tabular}




\section{Factor structure of FPQ-III for the study sample}

To the best of our knowledge, although the factor structure of the FPQ-III has been tested previously, the factor structure of the FPQ-III has not been tested in a community-based sample of individuals living with mixed chronic painful conditions. Standardized parameter estimates (eg, factor loadings and squared multiple correlations) were calculated (Table 4). Factor loadings refers to the correlation between the observed variables and the underlying factor, while the squared multiple correlation is the correlation between the variable and the other set of variables predicted using linear function. The factor loadings presented in Table 4 show the items' correlation with the latent factor. The factor loadings for fear of severe pain ranged between 0.38 and 0.82 ; fear of minor pain had a range between 0.50 and 0.69 ; and fear of medical pain had a range between 0.31 and 0.79 . All the items loaded above the recommended cutoff of 0.4 (refer to Table 4). Except for the items 16 (fear of medical pain) and 27 (fear of severe pain), the three subscales were composed of the exact same items as predicted in previous studies. The squared multiple correlations for severe fear of pain ranged between 0.40 and 0.73 ; the minor fear of pain had a range between 0.47 and 0.57 ; and medical fear of pain had a range between 0.54 and 0.72 .

Table 3 Results from logistic regression model predicting frequency of pain

\begin{tabular}{|l|l|l|l|}
\hline Frequency of pain & Odds ratio & $\mathbf{P}$-value & $\mathbf{9 5 \%} \mathbf{~ C l}$ \\
\hline Age & & & \\
$\quad$ I8-40 years & 0.57 & 0.01 & $0.39-0.84$ \\
Employment status & & & \\
$\quad$ No & 1.80 & 0.01 & $1.23-2.70$ \\
Fear of pain subscale & & & \\
$\quad$ Severe & 1.33 & 0.01 & $1.04-1.70$ \\
$\quad$ Minor & 0.94 & 0.60 & $0.75-1.22$ \\
Medical & 0.79 & 0.01 & $0.62-.1 .00$ \\
\hline
\end{tabular}

As presented in Table 5, the findings suggest that the internal consistency was good in this sample, ranging between 0.65 and 0.73 . The intercorrelations between all subscales were also positive and had a range between 0.49 and 0.57 , indicating moderate association, but certainly not complete overlap.

\section{Discussion}

The FPQ-III has been used widely to assess fear and anxiety associated with pain in clinical populations but not in a community-based sample of individuals living with mixed chronic painful conditions. Multiple studies have evaluated the applicability of the FPQ-III; however, its applicability and psychometric properties in individuals living with chronic pain from a community-based sample have never been tested before. The study also examined the association between domains of pain-related fear and duration and frequency of pain. The findings suggest that higher fear of severe pain and lower fear of medical pain are associated with longer duration and more frequent pain experience. The fear related to medical pain subscale of the FPQ-III measures pain associated with medical procedures (eg, receiving injection in the forearm), while the fear related to severe pain subscale measures fear related to nociception from a nonmedical-related exposure (eg, falling down a flight of stairs). As most medical procedures are preplanned, and have defined recovery time,

Table 5 Pearson's correlation and Cronbach's $\alpha$ for the FPQ-III subscales $(\mathrm{N}=490)$

\begin{tabular}{|l|l|l|l|l|}
\hline & $\begin{array}{l}\text { Severe } \\
\text { pain }\end{array}$ & $\begin{array}{l}\text { Minor } \\
\text { pain }\end{array}$ & $\begin{array}{l}\text { Medical } \\
\text { pain }\end{array}$ & Cronbach's $\alpha$ \\
\hline Severe pain & & & & 0.71 \\
Minor pain & $0.57^{\mathrm{a}}$ & & & 0.65 \\
Medical pain & $0.49^{\mathrm{a}}$ & $0.55^{\mathrm{a}}$ & & 0.73 \\
\hline
\end{tabular}

Note: Pearson's correlation

Abbreviation: FPQ-III, Fear of Pain Questionnaire-III.

Table 4 Factor loadings and squared multiple correlations of the FPQ-III

\begin{tabular}{|c|c|c|c|c|c|c|c|c|c|c|}
\hline Item no & I & 3 & 5 & 6 & 9 & 10 & 13 & 18 & 25 & 27 \\
\hline Severe FL & 0.66 & 0.75 & 0.78 & 0.78 & 0.74 & 0.78 & 0.82 & 0.61 & 0.62 & 0.38 \\
\hline$r$ & 0.46 & 0.73 & 0.64 & 0.73 & 0.70 & 0.69 & 0.66 & 0.59 & 0.40 & 0.45 \\
\hline Item no & 2 & 4 & 7 & 12 & 19 & 22 & 23 & 24 & 28 & 30 \\
\hline Minor FL & 0.58 & 0.63 & 0.69 & 0.53 & 0.69 & 0.65 & 0.68 & 0.66 & 0.60 & 0.50 \\
\hline$r$ & 0.51 & 0.52 & 0.51 & 0.52 & 0.57 & 0.56 & 0.47 & 0.52 & 0.55 & 0.35 \\
\hline Item no & 8 & II & 14 & 15 & 16 & 17 & 20 & 21 & 26 & 29 \\
\hline Medical FL & 0.78 & 0.79 & 0.75 & 0.48 & 0.31 & 0.71 & 0.49 & 0.57 & 0.60 & 0.60 \\
\hline$r$ & 0.68 & 0.72 & 0.58 & 0.55 & 0.54 & 0.60 & 0.62 & 0.58 & 0.68 & 0.67 \\
\hline
\end{tabular}

Note: $r$, squared multiple correlations.

Abbreviations: FL, factor loading; FPQ-III, Fear of Pain Questionnaire-III. 
participants may interpret them as acute, which may explain lower fear related to medical pain.

On the contrary, the uncertainty of exposure and longer traumatic recovery associated with pain related to accidental events (eg, being in an automobile accident measured by the fear of severe pain subscale of the FPQ-III) could elicit higher fear and anxiety. It is likely that participants with higher fear of severe pain may have developed an enhanced state of sensitivity or "hypervigilance" about pain, which could plausibly explain their report of longer and continuous state of pain. This information could be valuable for developing personalized psychosocial interventions aligning with individual patient differences in type of fear and anxiety related to pain. The analysis also suggests that longer duration and more frequent pain are strongly associated with age and unemployment. Together, these findings open up the possibility of using the FPQ-III as a device to identify those who may experience longer duration and more frequent pain.

The factor structure and reliability findings demonstrate that the FPQ-III is suitable to measure fear related to pain in community-based individuals living with mixed chronic pain conditions. The analyses confirmed the three-factor structure of the instrument and showed good internal consistency for the fear of severe and medical pain subscales and acceptable internal consistency for the fear of minor pain subscale. Although the internal consistency values from this sample are slightly different from previous studies, it is necessary to correlate the range of Cronbach's $\alpha$ with the number of items in the tool being tested. ${ }^{40}$ The findings also confirmed that fear and anxiety about pain can be classified into three domains: fear of severe pain, fear of minor pain, and fear of medical pain, as described in the FPQ-III.

While this investigation is unique in exploring the applicability of the FPQ-III in individuals living with chronic pain from a community-based sample, it has some limitations. The study method of an online survey limits the participation to only those individuals who are accustomed to computer use and have access to the Internet. Also, as the participants were not recruited from a pain clinic or hospital, the data related to pain condition and experience are entirely dependent on self-report and could not be verified. The majority of the study participants are female, which may limit generalizability. A study with a more even male-to-female distribution may have produced different results. Literature suggests that females often report greater pain sensitivity than do males and may be at higher risk of clinical pain. ${ }^{42,43}$ In addition, no information on weight, body mass index, disability, distress, basal-substance use/abuse behaviors, and treatment was collected, which may be an important covariate of fear of pain. Nevertheless, this study has an advantage, in that it demonstrates that the FPQ-III could be potentially applied to identify community-dwelling individuals living with various chronic pain conditions who are likely to experience longer duration and higher frequency of pain.

\section{Conclusion}

The present study shows that the FPQ-III is a valid and reliable tool for assessing fear and anxiety related to pain in individuals living with chronic pain from a communitybased sample, consistent with pain research with different population groups. The findings suggest that higher fear of severe pain and lower fear of medical pain are associated with longer duration and more frequent pain experience.

\section{Acknowledgment}

We acknowledge with gratitude all the individuals who participated in this study and the organizations and societies who promoted our survey on their websites.

\section{Author contributions}

All authors contributed to data analysis, drafting and revising the article, gave final approval of the version to be published, and agree to be accountable for all aspects of the work.

\section{Disclosure}

The authors report no conflicts of interest in this work.

\section{References}

1. Gaskin DJ, Richard P. The economic costs of pain in the United States. J Pain. 2012;13(8):715-724.

2. Dueñas M, Ojeda B, Salazar A, Mico JA, Failde I. A review of chronic pain impact on patients, their social environment and the health care system. J Pain Res. 2016;9:457-467.

3. de Souza JB, Grossmann E, Perissinotti DMN, de Oliveira Junior JO, da Fonseca PRB, Posso IP. Prevalence of Chronic Pain, Treatments, Perception, and Interference on Life Activities: Brazilian PopulationBased Survey. Pain Res Manag. 2017;2017:4643830.

4. Hassett AL, Aquino JK, Ilgen MA. The risk of suicide mortality in chronic pain patients. Curr Pain Headache Rep. 2014;18(8):436.

5. Bohman H, Jonsson U, Pärren A, von Knorring L, Olsson G, von Knorring AL. Prognostic significance of functional somatic symptoms in adolescence: a 15-year community-based follow-up study of adolescents with depression compared with healthy peers. BMC Psychiatry. 2012;12:90.

6. Ilgen MA, Zivin K, Austin KL, et al. Severe pain predicts greater likelihood of subsequent suicide. Suicide Life Threat Behav. 2010;40(6): 597-608.

7. Asmundson GJ, Parkerson HA, Petter M, Noel M. What is the role of fear and escape/avoidance in chronic pain? Models, structural analysis and future directions. Pain Manag. 2012;2(3):295-303.

8. Simons LE, Kaczynski KJ. The fear avoidance model of chronic pain: examination for pediatric application. J Pain. 2012;13(9):827-835. 
9. Crombez G, Eccleston C, Van Damme S, Vlaeyen JW, Karoly P. Fearavoidance model of chronic pain: the next generation. Clin J Pain. 2012;28(6):475-483.

10. Lyby PS, Aslaksen PM, Flaten MA. Variability in placebo analgesia and the role of fear of pain--an ERP study. Pain. 2011;152(10):2405-2412.

11. Vlaeyen JW, Linton SJ. Fear-avoidance and its consequences in chronic musculoskeletal pain: a state of the art. Pain. 2000;85(3):317-332.

12. Crombez G, Vlaeyen JW, Heuts PH, Lysens R. Pain-related fear is more disabling than pain itself: evidence on the role of pain-related fear in chronic back pain disability. Pain. 1999;80(1-2):329-339.

13. Leeuw M, Goossens ME, Linton SJ, Crombez G, Boersma K, Vlaeyen JW. The fear-avoidance model of musculoskeletal pain: current state of scientific evidence. J Behav Med. 2007;30(1):77-94.

14. Vlaeyen JW, Kole-Snijders AM, Boeren RG, van Eek H. Fear of movement/(re)injury in chronic low back pain and its relation to behavioral performance. Pain. 1995;62(3):363-372.

15. Philips HC. Avoidance behaviour and its role in sustaining chronic pain. Behav Res Ther. 1987;25(4):273-279.

16. Lethem J, Slade PD, Troup JD, Bentley G. Outline of a Fear-Avoidance Model of exaggerated pain perception--I. Behav Res Ther. 1983;21(4):401-408.

17. Crombez G, Van Damme S, Eccleston C. Hypervigilance to pain: an experimental and clinical analysis. Pain. 2005;116(1-2):4-7.

18. Waddell G, Newton M, Henderson I, Somerville D, Main CJ. A FearAvoidance Beliefs Questionnaire (FABQ) and the role of fear-avoidance beliefs in chronic low back pain and disability. Pain. 1993;52(2):157-168.

19. Crowley D, Kendall NAS. Development and initial validation of a questionnaire for measuring fear-avoidance associated with pain: the fear-avoidance of pain scale. J Musculoskelet Pain. 1999;7(3):3-19.

20. McNeil DW, Rainwater AJ 3rd. Development of the Fear of Pain Questionnaire--III. J Behav Med. 1998;21(4):389-410.

21. McCracken LM, Zayfert C, Gross RT. The Pain Anxiety Symptoms Scale: development and validation of a scale to measure fear of pain. Pain. 1992;50(1):67-73.

22. Miller RP, Kori SH, Todd DD. The Tampa Scale: a Measure of Kinesiophobia. Clin J Pain. 1991;7(1):51.

23. McNeil DW, Kennedy SG, Randall CL, et al. Fear of Pain Questionnaire-9: Brief assessment of pain-related fear and anxiety. Eur J Pain. 2018;22(1):39-48

24. Vambheim SM, Lyby PS, Aslaksen PM, Flaten MA, Åsli O, Martinussen LM. The Fear of Pain Questionnaire-III and the Fear of Pain Questionnaire-Short Form: a confirmatory factor analysis. J Pain Res. 2017; 10:1871-1878

25. Cardoso S, Esculpi D, Carvalho AR, et al. The European Portuguese adaptation of the Fear of Pain Questionnaire. Rev Bras Reumatol. 2016;56(5):377-383.

26. Asmundson GJ, Bovell CV, Carleton RN, McWilliams LA. The Fear of Pain Questionnaire-Short Form (FPQ-SF): factorial validity and psychometric properties. Pain. 2008;134(1-2):51-58.
27. Sperry-Clark JA, Mcneil DW, Ciano-Federoff L. Assessing chronic pain patients: The Fear of Pain Questionnaire - III. In: Vandercreek L, Jackson TL, editors. Innovations in Clinical Practice: A Source Book. Sarasota, FL: Professional Resources Press; 1999:293-305.

28. Albaret MC, Muñoz Sastre MT, Cottencin A, Mullet E. The Fear of Pain questionnaire: factor structure in samples of young, middle-aged and elderly European people. Eur J Pain. 2004;8(3):273-281.

29. Surveymonkey. Available from: https://www.surveymonkey.com/ r/72WPLMB. Accessed October 24, 2018.

30. Mittinty MM, Brennan DS, Randall CL, McNeil DW, Mittinty MN, Jamieson L. Influence of fear of pain and coping strategies on health-related quality of life and patient-anticipated outcomes in patients with chronic pain: cross-sectional study protocol. JMIR Res Protoc. 2017;6(9):e176.

31. Tsang A, Von Korff M, Lee S, et al. Common chronic pain conditions in developed and developing countries: gender and age differences and comorbidity with depression-anxiety disorders. J Pain. 2008;9(10):883-891.

32. Wade JB, Hart RP, Wade JH, Bajaj JS, Price DD. The relationship between marital status and psychological resilience in chronic pain. Pain Res Treat. 2013;2013:928473.

33. Saastamoinen P, Leino-Arjas P, Laaksonen M, Lahelma E. Socioeconomic differences in the prevalence of acute, chronic and disabling chronic pain among ageing employees. Pain. 2005;114(3):364-371.

34. Scher AI, Stewart WF, Ricci JA, Lipton RB. Factors associated with the onset and remission of chronic daily headache in a population-based study. Pain. 2003;106(1-2):81-89.

35. Blyth FM, March LM, Brnabic AJ, Jorm LR, Williamson M, Cousins MJ. Chronic pain in Australia: a prevalence study. Pain. 2001;89(2-3): 127-134.

36. McNeil DW, Helfer AJ, Weaver BD, Graves RW, Kyle BN, Davis AM. Memory of pain and anxiety associated with tooth extraction. $J$ Dent Res. 2011;90(2):220-224.

37. StataCorp. Stata Statistical Software: Release 14. College Station, TX: StataCorp LP; 2015.

38. Brown TA. Confirmatory Factor Analysis for Applied Research. New York: Guilford Publications. 2014.

39. Tavakol M, Dennick R. Making Sense of Cronbach's Alpha. Int J Med Edu. 2011;2:53-55.

40. Nunnally JC. Psychometric Theory. 2nd ed. New York: McGraw-Hill; 1978.

41. Devellis RF. Scale Development: Theory and Applications. Los Angeles: Sage; 2012:109-110.

42. Bartley EJ, King CD, Sibille KT, et al. Enhanced pain sensitivity among individuals with symptomatic knee osteoarthritis: potential sex differences in central sensitization. Arthritis Care Res (Hoboken). 2016;68(4):472-480.

43. Bartley EJ, Fillingim RB. Sex differences in pain: a brief review of clinical and experimental findings. Br J Anaesth. 2013;111(1):52-58.

\section{Journal of Pain Research}

\section{Publish your work in this journal}

The Journal of Pain Research is an international, peer reviewed, open access, online journal that welcomes laboratory and clinical findings in the fields of pain research and the prevention and management of pain. Original research, reviews, symposium reports, hypothesis formation and commentaries are all considered for publication
The manuscript management system is completely online and includes a very quick and fair peer-review system, which is all easy to use. Visit http://www.dovepress.com/testimonials.php to read real quotes from published authors. 